\title{
Thylacinus (Marsupialia: Thylacinidae) from the Mio-Pliocene boundary and the diversity of Late Neogene thylacinids in Australia.
}

Adam M Yates

Thylacinus yorkellus is described as a new, moderately small-bodied species of thylacinid from the latest Miocene or, more likely, earliest Pliocene of South Australia. The new species can be diagnosed by the autapomorphic presence a strongly developed precingulid that terminates in a cuspidule on the anterobuccal face of the paraconid of the lower molars and a tiny basal anterior cuspidule on $\mathrm{P}_{2}, \mathrm{P}_{3}$ and the lower molars. It is found by cladistic analysis to be the sister species of the recently extinct $T h$. cynocephalus and distinct from the approximately coeval Th. megiriani from the Northern Territory. New dentary material is described and referred to Th. megiriani. These add character data and allow this species to be re-diagnosed based on autapomorphic character traits. Each of the three known Late Miocene to Early Pliocene Thylacinus species (Th. potens, Th. megiriani and Th. yorkellus) suggest that, instead of declining, there was a modest radiation of Thylacinus in the Late Miocene. 
2 Adam M. Yates

3 Museums and Art Galleries of the Northern Territory

4 Museum of Central Australia, P.O. Box 831, Alice Springs, Northern Territory, 0871

5 Australia

6 Corresponding author: Adam M. Yates, Museum of Central Australia, P.O. Box 831, Alice

7 Springs, Northern Territory, 0871, Australia, ph. +61 (08) 89511148, email:

8 adamm.yates@nt.gov.au

9

10 


\section{Introduction}

12 The tragic tale of Thylacinidae, or the marsupial wolves, involves a sustained loss of diversity from an early to

13 middle Miocene high (Wroe, 2003) up to the final extermination of the last surviving population of Thylacinus

14 cynocephalus at our own hands in the early twentieth century (Thornback and Jenkins, 1982; Fisher and

15 Blomberg, 2011). Just when the Thylacinidae became restricted to a single species is an interesting question

16 that might relate to broadscale changes in Australian terrestrial ecosystems during the latter part of the

17 Cenozoic. It has been noted that the late Miocene diversity of thylacinids is severely depleted (Rich, 1991;

18 Wroe and Muirhead, 1999; Wroe, 2003), although the dearth of fossil deposits from this time is a confounding

19 factor. Nevertheless one popular account has suggested that the wolf-sized Th. potens from the Alcoota Local

20 Fauna (Woodburne, 1967) was the sole surviving lineage by this time and that it was directly ancestral to the

21 modern Th. cynocephalus (Archer, Hand and Godthelp, 1991).

22 Subsequently Tyarrpecinus rothi, a small plesiomorphic thylacinid that is separate from the genus Thylacinus, was discovered in the Alcoota Local Fauna demonstrating that at least two thylacinid lineages were surviving at this point in the Late Miocene (Murray and Megirian, 2000). However all thylacinids from younger Local Faunas belong to Thylacinus, indicating that $T y$. rothi was a late surviving relict that probably died out shortly after the deposition of the Alcoota Local Fauna. The discovery of Ty. rothi does not falsify the hypothesis that Th. potens was part of a single anagenetic lineage of large-bodied thylacinids that led directly to Th. cynocephalus. Therefore the scenario where Thylacinidae was reduced to a single lineage prior to the close of the Miocene remained a viable hypothesis.

A further large-bodied Thylacinus species, Th. megiriani, was discovered in the Ongeva Local Fauna which derives from a channel-fill in the Waite formation that overlies the Alcoota Local Fauna on Alcoota Station (Murray, 1997). The Ongeva Local Fauna correlates with the Beaumaris Local Fauna from the Black Rock Sandstone in the Port Philip Basin of south-eastern Australia based on the shared presence of Zygomaturus gilli (Megirian, Murray and Wells, 1996; Murray, 1997; Megirian et al., 2010). The Black Rock Sandstone also preserves a marine invertebrate fauna and has a robustly stratigraphically controlled age of 6.2-5.0 ma, an age that straddles the Mio-Pliocene boundary (Dickinson et al., 2002). Th. megiriani shares more derived features with the modern Th. cynocephalus than with Th. potens. Thus Th. megiriani could be interpreted as chronospecies on an anagenetic lineage leading from Th. potens to Th. cynocephalus. At the time of its description Th. megiriani was known only from its holotype,a single broken maxilla with worn and damaged teeth. However two large thylacinid dentary fragments have been found in the Ongeva Local Fauna since the initial publication that can be referred to this species. Character data from these specimens has been incorporated into a phylogenetic analysis of thylacinid relationships (Yates, 2014) but they have not been described or adequately illustrated in the scientific literature.

There is a further thylacinid from the penecontemporaneous Curramulka Local Fauna of South Australia (Pledge, 1992) that sheds light on the number of thylacinid lineages present in Australia during the latest Miocene and earliest Pliocene. This thylacinid is described here as a new species. In addition the new mandibular specimens of Th. megiriani are described and the species diagnosed with autapomorphic characters. This new data casts strong doubt on the hypothesis of a single anagenetic lineage of Thylacinus in the late Neogene of Australia. 


\section{Systematic Palaeontology}

52 Dasyuromorphia Gill, 1872

53 Thylacinidae Bonaparte, 1838

54 Thylacinus Temminck, 1824

55 Thylacinus yorkellus sp. nov.

56 urn:Isid:zoobank.org:act:D176F98E-740B-4E37-A491-3AFDCCC1CD50

57 Holotype. South Australian Museum (hereafter SAM) P29807, incomplete left dentary with C, $\mathrm{P}_{1-3}$ and $\mathrm{M}_{2-3}$ (Fig.

58 1-2, Table 1).

59 Referred specimen. SAM P38799, crown of right $\mathrm{M}_{3}$ (Fig. 3-4, Table 1).

60 Locality and stratigraphic age. Corra-Lynn Cave, approximately $3 \mathrm{~km}$ south of Curramulka, York Peninsula,

61 South Australia. Late Miocene or, more likely, early Pliocene in age.

Etymology. From York Peninsula and the diminutive suffix -ellus (Latin), referring to its small size relative to $T$. cynocephalus.

Diagnosis. Th. yorkellus differs from all other thylacinids by the presence of the following autapomorphies. The lower molars have a strongly developed precingulid that terminates in a cuspidule on the anterobuccal face of the paraconid and a tiny basal anterior cuspidule on $\mathrm{P}_{2}, \mathrm{P}_{3}$ and the lower molars. Aside from these two autapomorphies it can be further distinguished from Th. macknessi and all thylacinids not in the genus Thylacinus by the complete absence of metaconids on $\mathrm{M}_{2}, \mathrm{M}_{3}$ and, presumably, $\mathrm{M}_{4}$. It can be further distinguished from Th. potens by its smaller size (estimated adult body mass of 16-18 kg vs. 39-56 kg for Th. potens; Yates, 2014), by the presence of wide diastemata between each of the lower premolars as well between $P_{3}$ and $M_{1}$, and by the presence of deep cleft-like carnassial notches on the lower molars. It can be further distinguished from Th. megiriani by its smaller size (estimated body mass of Th. megiriani is $57 \mathrm{~kg}$; Wroe, 2001), wider diastemata separating $P_{3}$ from $M_{1}$ and $P_{2}$ from $P_{3}$, its relatively gracile and buccolingually compressed anterior dentary lacking a ventrolateral torus, the complete absence of any trace of the metaconid on the lower molars, and by the presence of deep cleft-like carnassial notches on the lower molars. Lastly, it can be further distinguished from $T$. cynocephalus by the lengths of both $P_{2}$ and $P_{3}$ exceeding that of $M_{1}$ and by the presence of a diastema between the canine and $\mathrm{P}_{1}$.

78 Remarks. Pledge (1992) figured and briefly described the holotype specimen in his description of the Curramulka Local Fauna. He suggested that it might belong to an undescribed species but declined to name it.

80 With our improved knowledge of thylacinid diversity and the addition of a second specimen showing the same 81 autapomorphic characters of the molars as the holotype, there is now sufficient evidence to warrant the 82 naming of a new species. 


\section{Description}

85 The holotype includes the incisor alveoli, the canine, all three premolars, $M_{2}, M_{3}$ and the alveolus for $M_{1}$ (Fig. 1-

86 2, Table 1). Posteriorly the dentary has broken off at the level of the posterior end of $M_{3}$, so that $M_{4}$ is missing.

87 The dentary is transversely compressed, as it is in Th. cynocephalus but unlike the transversely broad, robust

88 dentaries of Th. megiriani and some Th. potens. The dentary of Th. yorkellus differs further from that of Th.

89 megiriani and Th. potens in lacking a thickened torus along the ventrobuccal margin, below the mental

90 foramina. The dentary depth below the anterior root of $\mathrm{M}_{2}$ (the posteriormost level at which this

91 measurement can be made) is $24.5 \mathrm{~mm}$ which lies within the range of $T h$. cynocephalus. Given that the length

92 of the lower molar row and the heights of the individual molars lie below the range seen in Th. cynocephalus, I

93 propose that the holotype $T h$. yorkellus has a deeper jaw relative to tooth size in comparison to the former

94 species. A relatively deep dentary is also seen in some, but not all, specimens of Th. potens (Yates, 2014). The

95 buccal surface of the dentary is pierced by three mental foramina set approximately at the mid height of the dentary, although it is possible that a fourth was present in what is now a large area of missing bone below $\mathrm{P}_{3}$ (Fig. 2). The anterior mental foramen is large anteriorly facing opening with a diameter of $3.2 \mathrm{~mm}$ located below the anterior root of $P_{2}$. The two close-set posterior mental foramina are placed below $M_{2}$ and the anterior margin of $\mathrm{M}_{3}$, respectively. These openings are smaller, with anteroposterior diameters of 2.1 and 1.4 $\mathrm{mm}$, respectively. In buccal view the alveolar margin is concave with $\mathrm{P}_{3}$ set lower than the rest of the preserved tooth row. The symphyseal surface extends posteriorly to the level of the anterior margin of $P_{3}$.

The canine has a procumbent root and a vertically projecting crown. The tip is gently recurved so that the anterior margin in lateral view is convex and the posterior margin is concave. In anterior view the crown has a weak lingual curvature. The cross-section of the crown is a slightly buccolingually compressed oval. A weakly developed carina extends along the anterolingual margin of the crown, from base to apex. The distal surface is rounded and smooth. The measurements of the canine are given in Table 1.

A diastema of $3.3 \mathrm{~mm}$ separates the canine alveolus from that of $P_{1} . P_{1}$ is a smaller, lower-crowned tooth than all of the other postcanine teeth. In occlusal view is elongately ovoid with the long axis oriented anteroposteriorly. Although the tip of the protoconid is well worn, it is clear that the unworn tooth would have had a height less than its anterior-posterior length. The apex of the protocone is located in the anterior half with an elongate heel extending posterior to it. The heel has a sharp posterior corner which forms an incipient cuspidule. In buccal view the posterior margin of the protoconid curves gently down to the distal heel. A weakly developed cristid extends along the anterior margin of the protoconid. The tooth has no other cristids or cuspidules.

115 A diastema of $2.8 \mathrm{~mm}$ sepparates $P_{1}$ from $P_{2}$. $P_{2}$ differs from $P_{1}$ in being larger (Table 1 ) and proportionately taller. The apex of the triangular protoconid is less skewed to the anterior side of the tooth, being placed slightly mesial to the mid length. A weak cristid extend up the anterior side of the protoconid. There is a minute tubercle-like cuspidule developed at the base of this anterior cristid. A posterior cristid extends from the apex of the protoconid to the posterior corner of the basal heel. A distinct inflection in the buccal profile marks the change from the heel to the posterior margin of the protoconid. 
121 A long diastema of $6.4 \mathrm{~mm}$ sepparates $P_{2}$ from $P_{3} . P_{3}$ is larger than, $P_{2}$ and differs from it in a number of subtle 122 features. $P_{3}$ shows a greater development of the anterior basal cuspidule than in $P_{2}$. The large protoconid is 123 centrally located and triangular in buccal view. Both anterior and posterior margins bear cristids. In occlusal 124 view the crown is widest posteriorly, where the heel forms an incipient talonid basin. A shallow notch in the 125 buccal profile separates the posterior heel from the protoconid, and the posterior heel forms a protrusive 126 cuspidule with a worn tip.

$127 \mathrm{M}_{1}$ is missing, and the lingual alveolar margin of the dentary is missing from the level of the posterior root of $128 P_{3}$, posteriorly. Nevertheless the buccal side of the $M_{1}$ alveolus is separated from $P_{3}$ by a diastema of $3.0 \mathrm{~mm}$, 129 whereas there is no diastema between the alveolus of $M_{1}$ and $M_{2}$.

$130 \quad \mathrm{M}_{2}$ consists of two large trigonid cusps (paraconid and protoconid) and three far smaller cusps (hypoconid, 131 hypoconulid and entoconid) surrounding the talonid basin. The most remarkable feature of $M_{2}\left(a n d M_{3}\right)$ is the 132 strength of the precingulid, which forms a sharp-edged shelf that terminates in a well-developed cuspidule on the anterobuccal face of the base of the paraconid. The precingulid slopes steeply posteroventrally from this cuspidule and terminates near the base of the crown level with the anterior margin of the protoconid. The paraconid is well developed and triangular in occlusal view. A minute cuspidule is developed on the anterior slope of the paraconid, near the base of the crown, at about the same level as the anterobuccal cuspidule of the precingulid. The protoconid forms the largest cusp of $\mathrm{M}_{2}$. In buccal view the anterior margin of the protoconid curves posteriorly towards the apex, however this shape has been created by wear. A distinct, teardrop shaped wear facet is developed at the tip of the protoconid and extends down its anterior side, along the course of the paracristid. A deep carnassial notch is developed between the paraconid and protoconid, dividing the paracristid into two sections. There is no trace of a protocristid or a metaconid on the posterior side of the protoconid, although the cristid obliqua extends approximately half way up this surface. The cristid obliqua is also divided into two sections by a deep carnassial notch, this time separating the protoconid from the hypoconid. In buccal and lingual view the talonid is set distinctly lower than the trigonid. In occlusal view its buccolingual width is slightly greater than that of the trigonid. All of the cusps of the talonid are highly worn and flat-topped. The largest of these and the most strongly projecting is the buccally placed hypoconid. The posteriorly located hypoconulid has been virtually obliterated by wear and is only recognisable as a slight thickening of the enamel around the posterior rim of the wear facet. The entoconid is placed on the lingual side of the talonid, slightly inset from the lingual margin of the crown. A short ridge extends posterobuccally from its apex towards the hypoconulid. A postcingulid extends obliquely up the posterior surface of the hypoconid from a basally located point on the buccal side to a more apical point on the lingual side. $M_{3}$ is very much like $M_{2}$, differing in the following respects. The minute anterior cuspidule at the base of the paraconid is less well-developed. The protoconid is taller, and the cristid obliqua extends for less than half its height up the posterior surface. The talonid is slightly narrower than the trigonid and the hypoconulid forms a low conical cuspid. The posterobuccal ridge extending from the apex of the entoconid joins the anterior base of the hypoconulid, thus creating anoval basin that is separated from, and much smaller than, the main talonid basin. A low but sharp postcristid between the hypoconulid and the entoconid forms the posterolingual margin of this oval basin. The postcingulid is very reduced, and is little more than a shallow depression on the posterior surface of the hypoconid. 
160 The $M_{3}$ of SAM P38799 shows some minor differences from the holotype but the main features are the same, 161 including the distinctive precingulid terminating in an anterobuccal cuspidule (Fig. 3-4, Table 1). In this

162 specimen the anterior cuspidule at the base of the paraconid is better developed than in either of the two

163 molars of the holotype, and has an incipient preparacristid leading from it towards the apex of the paraconid.

164 The talonid is as wide as the trigonid and the entoconid appears to lack the posterobuccal ridge that links it to

165 the hypoconulid.

\section{Body mass estimate}

167 Calculating from the third lower molar length regression formula, derived from the dasyuromorphian-only data 168 set of Myers (2001), a body mass estimate of $17.8 \mathrm{~kg}$ is obtained for the holotype and $15.9 \mathrm{~kg}$ for SAM P38799.

169 These estimates are well below the average body mass of $29.5 \mathrm{~kg}$ for recent Tasmanian Th. cynocephalus

170 (Paddle, 2000) but are not outside the range estimated for mainland Holocene samples of this species (Letnic,

171 Fillios and Crowther, 2012). However, it is clear that Th. yorkellus was a far smaller species than either Th.

172 potens or Th. megiriani which have estimated body masses ranging between 38.7 and $57.3 \mathrm{~kg}$ (Wroe, 2001;

173 Yates, 2014).

174 Thylacinus megiriani Murray, 1997

175 Holotype. Museum and Art Gallery of the Northern Territory (hereafter designated NTM) P9618, fragmentary 176 left maxilla with $\mathrm{P}^{1-3}$ and $\mathrm{M}^{1-3}$

177 Referred specimens. NTM P4376, anterior fragment of a right dentary containing the alveoli with broken roots 178 for $P_{2}, P_{3}$ and $M_{1}$ and the empty alveolus for $M_{2}$ (Fig. 5-7). NTM $P 4377$, posterior fragment of a right dentary 179 containing an incomplete $\mathrm{M}_{4}$ (Fig. 8-10).

180 Locality and stratigraphic age. 'South Quarry', an excavation on the south-western side of 'Hill 1' (Woodburne 181 1967) an erosional remnant of the upper Waite Formation on the Alcoota Fossil Reserve. Ongeva Local Fauna, 182 latest Miocene or earliest Pliocene in age.

183 Diagnosis. Th. megiriani differs from all other thylacinids by the presence of the following two

184 autapomorphies. There is a a short, lobe-like postcingulum between the metastyle and protocone of $\mathrm{M}^{2}$. A 185 hypertrophied torus is developed along the ventrobuccal margin of the dentary so that its buccolingual width 186 at the level of $\mathrm{P}_{3}$ is greater than $75 \%$ of its depth at the same level. The presence of a small stylar cusp E on $\mathrm{M}^{2}$ 187 and $\mathrm{M}^{3}$ might also be an autapomorphic reversal within the genus Thylacinus but the optimisation of the 188 character is ambiguous due to its presence in the closely related outgroup, Wabulacinus ridei, and the absence of a preserved $\mathrm{M}^{2}$ or $\mathrm{M}^{3}$ for Th. macknessi. Similarly the presence of a vestigial metaconid and metacristid on $\mathrm{M}_{4}$ (and presumably the other lower molars) is ambiguous due to the presence of metaconids in Th. macknessi and their absence in Th. potens. This may represent an autapomorphic reversal in Th. megiriani or a case of convergent loss in Th. potens and the Th. yorkellus + Th. cynocephalus clade. Th. megiriani can be further distinguished from Th. macknessi and all non-Thylacinus thylacinids by: its greater size; the great reduction of the size of the paracone relative to the metacone; elongation of the postmetacrista, so that it is greater than $52 \%$ the length of the tooth in $\mathrm{M}^{2}$ and $\mathrm{M}^{3}$. It can be further distinguished from $T$. potens by: the long axis of $\mathrm{P}^{1}$ 196 aligned with those of the other upper premolars; the length of $\mathrm{M}^{1}$ is greater than its width; the complete 
absence of a precingulum on $\mathrm{M}^{1}$ and $\mathrm{M}^{3}$; the absence of a metaconule on all upper molars; $\mathrm{M}^{3}$ much longer $(>5 \%)$ than $M^{2} ; M^{3}$ longer than wide; presence of a diastema between $P_{3}$ and $M_{1}$.

Remarks. The new dentary specimens cannot be referred to Th. megiriani on the basis of autapomorphic characteristics due to their fragmentary nature and lack of overlap with the holotype maxilla. However the apparent reversal to the presence of an, albeit vestigial, metaconid in NTM P parallels the reappearance of a tiny tubercular stylar cusp Ein the upper molars of the holotype, indicating that the two features may be not be independent in thylacinids and provides further support for the referral of the dentary fragment NTM P4377. It is interesting to note that the expression of the metaconid and stylar cusp E consistently covary in all known thylacinids, ie. taxa either possess both cusps or neither, never one or the other.

Furthermore the new dentary fragments derive from the same level in the same quarry as the holotype, are of an appropriately large size, and can be distinguished from Th. potens, which is the only other large-bodied thylacinid known from a similar time and place. For these reasons it is reasonable to refer them to $T h$. megiriani.

\section{Description of the new material}

The anterior dentary fragment (NTM P4376; Fig. 5-7, Table 2) has only broken roots and empty alveoli and does not contain any tooth crowns. This coupled with poor preservation means that it is not immediately obvious exactly which teeth the roots and alveoli belong to and therefore the disposition of the teeth in the jaw. However several lines of evidence indicate that the posterior two empty alveoli are for the anterior and posterior roots of $\mathrm{M}_{2}$, respectively, while the posterior two projecting root stumps are the anterior and posterior roots of $M_{1}$. Anterior to the molar alveoli there are the broken roots and alveoli of $P_{2}$ and $P_{3}$ (Fig. 7). Evidence for this interpretation comes from a partial bridge of finished bone between the second and third preserved alveoli, indicating that there was a diastema between two different teeth in this position, rather than these alveoli representing the anterior and posterior alveoli of the same tooth. The posterior limit of symphyseal surface is level with the anterior margin of the fourth alveolus. As the posterior end of the symphysis draws level with $\mathrm{P}_{3}$, or at least the diastema between $\mathrm{P}_{2}$ and $\mathrm{P}_{3}$ in all thylacinid specimens examined, the third and fourth alveoli in NTM P4376 should represent the anterior and posterior alveoli for $\mathrm{P}_{3}$. From the alveoli it can be seen that there was no diastema between $M_{1}$ and $M_{2}$, but there was a short diastema of 3.6 $\mathrm{mm}$ between $P_{3}$ and $M_{1}$, and a slightly longer diastema of $4.0 \mathrm{~mm}$ between $P_{2}$ and $P_{3}$.

The dentary is dorsoventrally shallow but buccolingually thickened, giving it a distinctly robust appearance. Adding to the thickness of the jaw is a strong torus developed along the ventrobuccal margin of the dentary from a point level with the midlength of $P_{2}$ to one level with the distal end of $M_{1}$. At the maximum thickness of the torus (level with the posterior root of $P_{3}$ ) the dentary measures $20.8 \mathrm{~mm}$ wide, which approaches the dorsoventral depth of the dentary at the same level $(27.0 \mathrm{~mm})$. The buccal surface of the dentary, above the ventrobuccal torus, is pierced by three mental foramina. The anterior-most mental foramen lies anterior to the alveoli for $\mathrm{P}_{2}$, the middle foramen lies level with the anterior end of $\mathrm{P}_{3}$, and the posterior foramen lies level with the posterior end of $M_{1}$. 
234 The second specimen (NTM P4377; Fig. 8-10, Table 2) is a small fragment from the posterior end of a right dentary including a partial $\mathrm{M}_{4}$ and the anterior base of the coronoid process. The lingual surface of the dentary is gently convex dorsoventrally, whereas the buccal surface bears a ridge that slopes posterodorsally to merge with the leading margin of the coronoid process. The buccal ridge forms the lower border of a flat dorsobuccally facing surface that occurs below the fourth lower molar. The ventral part of the dentary is missing so the depth to height ratio cannot be measured. The incomplete $\mathrm{M}_{4}$ includes the talonid and the posterior side of the protoconid. The protoconid is far taller than the talonid with an almost vertically oriented posterior margin. The protocristid extends from the apical tip of protoconid to a tubercle about half-way down the posterior face of the protoconid (Fig. 10). This tiny tubercle appears to be a vestigial remnant of the metaconid which is usually absent in derived species of Thylacinus. Two weakly developed cristids extend ventrally from the tubercle. The two cristids diverge at a highly acute angle. The more buccally placed cristid is the cristid obliqua. It extends to the base of the protoconid and up the anterior face of the hypoconid. A shallow, weakly developed carnassial notch is created between the hypoconid and the protoconid. This notch is similar to the weak notches developed on the lower molars of Th. potens and unlike the deep clefts that can be observed in the carnassial notches of the lower molars of Th. yorkellus and Th. cynocephalus. The lingual cristid that branches from the tubercle on the posterior face of the protoconid is interpreted as a metacristid. It terminates at the base of the protoconid without extending onto the talonid. Its presence strengthens the interpretation of the tubercle as a vestigial metaconid. The moderately large, conical hypoconid comprises the talonid which bears no other cusps. The anterobuccal face of the hypoconid is planed off by an oblique wear facet that faces buccodorsally. The weak cristid obliqua extends directly anteriorly from the apex of the hypoconid. The anterolingual rim of the hypoconid is rounded, lacking a postcristid.

\section{Cladistic Analysis}

256

Th. yorkellus was included in an earlier cladistic analysis of thylacinid relationships (Yates, 2014). This analysis already included data from the mandibular specimens of Th. megiriani described in this paper. The same characters from the previous were employed with one modification to character 36 . Previously this character simply described the absence (0) or presence (1) of a carnassial notch in the cristid obliqua of the lower molars. In the present analysis the derived state is divided into two states: a weakly-developed shallow carnassial notch (1) or a deep, strongly-developed carnassial notch (2). The multistate character is treated as ordered. The score for character 34 (metaconid size in $\mathrm{m}_{2-4}$ ) of Thylacinus megiriani was changed from 2 (completely absent) to 1 (present as a minute cuspidule) in the light of the new evidence presented above.

The resulting matrix (Appendix 1) was subjected to a maximum parsimony analysis in PAUP 4.0b (Swofford, 2002) using the following settings: heuristic search; random addition sequence with 500 replicates; and TBR branch-swapping algorithm. The strength of the internal nodes was tested with a bootstrap analysis (1000 bootstrap replicates, heuristic searching with 50 addition sequence replicates).

The search resulted in two equally most parsimonious trees of 93 steps. The topologies of these two trees are completely congruent with the two trees obtained in the earlier analysis (Yates, 2014) with the loss of resolution entirely the result of a variable position of Maximucinus muirheadae. If this taxon is pruned $a$ posteriori a fully resolved tree is obtained (fig. 11a). Th. yorkellus is found to be the sister species of the modern Th. cynocephalus. The Th. yorkellus $+T h$. cynocephalus is relatively robust with the second highest 
bootstrap score of all the internal clades (71\%, fig. 11b). Nevertheless missing data reduces the number of unambiguous apomorphies of this clade to one: the presence of a deep, well-developed carnassial notch in the cristid obliqua on each of the lower molars.

\section{Discussion}

The recognition of Th. yorkellus increases the number of Thylacinus species in the late Miocene - earliest Pliocene interval to three: Th. potens, Th. megiriani and Th. yorkellus. A fourth lineage, that of the recent Th. cynocephalus, can also be inferred to have arisen in this period (Fig. 12). None of the local faunas that produced the three known species can be directly dated but they do appear to form a stratigraphic sequence. The Ongeva Local Fauna occurs in a channel incised into sediments that overlie those that contain the Alcoota Local Fauna, directly demonstrating that the former is younger than the latter (Megirian, Murray and Wells, 1996). However the absolute age difference between them is probably not great because many species are shared between the two deposits including the biostratigraphically important Kolopsis torus (Megirian, Murray and Wells, 1996). The presence of Zygomaturus gilli in the Ongeva Local Fauna indicates that it may be correlated with the Beaumaris Local Fauna from the Black Rock Sandstone of Port Phillip Bay (Megirian, Murray and Wells, 1996). The Beamaris Local Fauna straddles the Mio-Pliocene boundary on the basis of local stratigraphic controls and its included marine invertebrate fauna (Dickinson et al, 2002). The difference in age between the Ongeva Local Fauna and the Curramulka Local Fauna, or even their relative positions with respect to each other, is difficult to determine. Pledge estimated that the deposit was late Miocene in age which would make it roughly contemporaneous with, or possibly older than the Ongeva Local Fauna. However a constrained seriation analysis clustered the Curramulka Local Fauna with younger Pliocene local faunas, that were given the age-name Tirarian while the Ongeva Local Fauna was clustered with the Beaumaris and Alcoota Local Fauna in the Waitean Age (Megirian et al. 2010). A younger age for the Curramulka Local Fauna is supported by the presence of a number of macropodid genera that are not known from the older Waitean fauna, including: Baringa, Troposodon and Protemnodon (Pledge, 1992). Nevertheless the Curramulka Local Fauna is probably one of the oldest Tirarian assemblages due to its total lack of rodent remains, despite intensive fine sieving of the silty matrix and presence of numerous other small vertebrates (Pledge, 1992). Thus an early Pliocene age of 4.5 ma or older would appear likely based on the timing of the appearance of rodents in other fossil deposits in Australia (Breed and Ford, 2007).

These three deposits do seem to form a stratigraphic sequence, and the sequence matches the branching order of the species of Thylacinus recovered in the cladistic analysis, supporting the hypothesis of an anagentic lineage. However, the time difference between them is probably too small for a plausible anagenetic sequence. It is quite likely that all three local faunas span no more than 2 or $3 \mathrm{ma}$, from 5 ma to 7 or $8 \mathrm{Ma}$. If Th. potens, Th. megiriani and Th. yorkellus did indeed form an anagenetic lineage then the turnover of morphologically distinct forms would appear to be unrealistically fast, especially given the known range of Th. cynocephalus is nearly four million years (based on the late Pliocene age of the Chinchilla Local Fauna). Furthermore each of these species can be diagnosed with autapomorphies, suggesting that none is an ancestor of any other. 
310 Thus it would appear that for a brief period in the latest Miocene through to the earliest Pliocene the genus

311 Thylacinus experienced a modest evolutionary radiation (Fig. 12). However the products of this radiation were

312 short-lived and by the late Pliocene there is no indication of any surviving thylacinid species other than Th.

313 cynocephalus (Dawson 1982). Unfortunately the Pliocene record of Thylacinus is fragmentary and sparse

314 (Mackness et al. 2002). Louys and Price (in press) report two specimens in the Queensland Museum that have

315 been identified as Th. rostralis (=Th. cynocephalus) and genuinely derive from the Chinchilla Local Fauna. Apart

316 from these specimens, and Th. yorkellus, all other Pliocene occurences of Thylacinus are specifically

317 indeterminate (Mackness et al. 2002).

\section{Acknowledgements}

320 I thank Ben McHenry of the South Australian Museum for access to the thylacinid specimens in his care. I also thank Mary-Anne Binnie, also from the South Australian Museum, for organising a loan of material from that institution. Eric Scott and an and an anonymous reviewer improved the manuscript with their helpful comments. All photographs used in this paper were taken by Steven Jackson, except figure 10 which was taken by the author.

\section{References}

327 Archer M, Hand SJ, Godthelp H. 1991. Riversleigh. The story of animals in ancient rainforests of inland 328 Australia. Sydney: Reed Books.

Bonaparte CLL. 1838. Synopsis vertebratorium systematis. Nuovi Annual, Science and Nature, Bologna 2: 105330133.

331 Breed W, Ford F. 2007. Native Mice and Rats. Australian natural history series. Collingwood: CSIRO Publishing.

332 Cohen KM, Finney SC, Gibbard PL, Fan J-X. 2013. The ICS International Chronostratigraphic Chart. Episodes 36: 333 199-204.

334 Dawson L. 1982. Taxonomic status of fossil thylacines (Thylacinus, Thylacinidae, Marsupialia) from late 335 Quaternary deposits in Eastern Australia. In: Archer M, ed. Carnivorous Marsupials. Sydney: Surrey Beatty and 336 Sons and the Royal Zoological Society of New South Wales, 527-536.

Dickinson JA, Wallace MW, Holdgate GR, Gallagher SJ Thomas L. 2002. Origin and timing of the MiocenePliocene unconformity in southeast Australia. Journal of Sedimentary Research 72: 288-303.

339 Fisher DO, Blomberg SP. 2012. Inferring Extinction of Mammals from Sighting Records, Threats, and Biological 340 Traits. Conservation Biology 26: 57-67.

341 Gill T. 1872. Arrangement of the families of mammals with analytical tables. Smithsonian Miscellaneous 342 Collections 2: 1-98. 
343 Letnic M, Fillios M, Crowther MS. 2012. Could Direct Killing by Larger Dingoes Have Caused the Extinction of

344 the Thylacine from Mainland Australia? PLOS ONE 7(5): e34877. doi:10.1371/journal.pone.0034877

345 Louys J, Price GJ. In press. The Chinchilla Local Fauna: an exceptionally rich and well-preservedPliocene

346 vertebrate assemblage from fluviatile deposits of south-eastern Queensland, Australia. Acta

347 Palaeontologica Polonica. http://dx.doi.org/10.4202/app.00042.2013

Mackness BS, Wroe S, Wilkinson C, Wilkinson D. 2002. Confirmation of Thylacinus from the Pliocene Chinchilla Local Fauna. Australian Mammalogy 24: 237-241.

351 Megirian D, Murray P, Wells R. 1996. The Late Miocene Ongeva Local Fauna of central Australia. The Beagle:

352 Records of the Museums and Art Galleries of the Northern Territory 13: 9-38.

353

354

355

356

357

358

359

360

Megirian D, Prideaux GJ, Murray PF, Smit N. 2010. An Australian land mammal age biochronological scheme. Paleobiology 36: 658-671.

Murray PF. 1997. Thylacinus megiriani, a new species of thylacine (Marsupialia: Thylacinidae) from the Ongeva Local Fauna of Central Australia. Records of the South Australian Museum 30: 43-61.

Murray PF, Megirian D. 2000. Two new genera and three new species of Thylacinidae (Marsupialia) from the Miocene of the Northern Territory, Australia. The Beagle: Records of the Museums and Art Galleries of the Northern Territory 16: 145-162.

Myers TJ. 2001. Prediction of marsupial body mass. Australian Journal of Zoology 49: 99-118.

Paddle R. 2000. The last Tasmanian tiger: the history and extinction of the thylacine. Cambridge: Cambridge University Press.

Pledge NS. 1992. The Curramulka Local Fauna: A new late Tertiary Fossil Assemblage from Yorke Peninsula, South Australia. The Beagle: Records of the Museums and Art Galleries of the Northern Territory 9: 115-142.

Rich TH. 1991. Monotremes, Placentals and Marsupials: their record in Australia and its biases. In: Vickers-Rich P, Monaghan JM, Baird RF, Rich TH, eds. Vertebrate Palaeontology of Australasia. Melbourne: Pioneer Design Studio,893-1070.

Swofford DL. 2002. PAUP* phylogenetic analysis using parsimony (* and other methods). Version 4. Sunderland, MA: Sinauer Associates.

Temminck CJ. 1824. Monographies de Mammalogie. Tom. 1. Paris: Dufour,. 60-65.

Thornback J, Jenkins M. 1982. The IUCN mammal red data book, Part 1. Gland: International Union for Conservation of Nature and Natural Resources.

Woodburne MO. 1967. The Alcoota Fauna, central Australia. Bulletin of the Bureau of Mineral Resources Geology and Geophysics, Australia 87: 1-187. 
376 Wroe S. 2001. Maximucinus muirheadae, gen. et sp. nov. (Thylacinidae: Marsupialia), from the Miocene of 377 Riversleigh, north-western Queensland, with estimates of body weights for fossil thylacinids. Australian

378 Journal of Zoology 49: 603-614.

379 Wroe S. 2003. Australian marsupial carnivores: Recent advances in palaeontology. In: Jones M, Dickman C, 380 Archer M, eds.Predators with Pouches: The Biology of Marsupial Carnivores. Collingwood: CSIRO Publishing, 381 102-123..

382 Wroe S, Muirhead J. 1999. Evolution of Australia's marsupicarnivores: Dasyuridae, Thylacinidae, 383 Myrmecobiidae, Dasyuromorphia incertae sedis and Marsupialia incertae sedis. Australian Mammalogy 21: 1038411.

385 Yates AM. 2014. New craniodental remains of Thylacinus potens (Dasyuromorphia: Thylacinidae), a carnivorous 386 marsupial from the late Miocene Alcoota Local Fauna of central Australia. PeerJ 2:e547; DOI 10.7717/peerj.547

388 Appendix 1. Character-Taxon Matrix

389 The character list is provided in Yates (2014).

390 Barinya wangala

3910 ? 0000010000000000000001000000000000000000

392 Antechinus flavipes

393000001000000000000000000000010000000000000

394 Muribacinus gadiyuli

39501 ? ?? ? ? ? 10000000000000001000 ? 10000000000 ? 0

396 Badjcinus turnbulli

39700 ? 01000 ? 00 ? 0 ? 000000 ? ? 100000001 ? 2010100010

398 Mutpuracinus archibaldi

3990 ? 0 ? 000010001000000000010000001 ? ? 010001000

$400 \quad$ Nimbacinus dicksoni

4010001100010001 ? 000000 ? ? 010 ? 0001 ? ? 1010000000

402 Nimbacinus richi

403 ? 00??000100010?0001000010000111? 101000 ? 000

404 Maximucinus muirheadae

405 ? ? ? ? ? ? ? ? ? ? ? ? 10 ? 0200 ? ? ? ? 10 ? ? ? ? ? ? ? ? ? ? ? ? ? 1

406 Ngamalacinus timmulvaneyi

407 ? 1 ? ? ? 1001 ? 00 ? ? 0 ? 00000 ? 000 ? 10 ? ? ? ? 1011100010

408 Wabulacinus ridei

40900 ? ? ? ? ? ? ? 1 ? 11 ? 021111 ? ? 10111 ? ? 01 ? ? 11001 ? 1 ? 0

410 Tyarrpecinus rothi

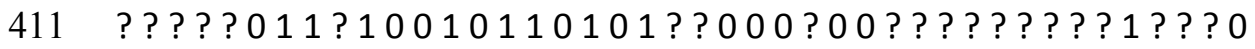

412 Thylacinus macknessi 
413 ?? ? ? ? ? ? ? 0 ? 11 ? 02 ? ? 10 ? ? 10 ? ? ? ? 01102111010110

414 Thylacinus potens

415 ?? 1 ? ? 0111001 ? 0122210001 ? 100010002221011102

416 Thylacinus megiriani

417111 ? ? 001 ? 21 ? 001 ? 22 1111111001 ? 111 ? 221 ? 1 ? ? 02

418 Thylacinus cynocephalus

419210111000211111222111110121101112221011101

420 Thylacinus yorkellus

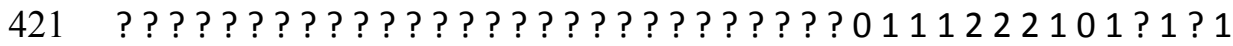

422

423 
1

Thylacinus yorkellus, holotype SAM P29807, incomplete left dentary.

Photographs of the specimen. (A) lateral view. (B) medial view. (C) dorsal view. Scale bar = $50 \mathrm{~mm}$. Photographs by Steven Jackson. 

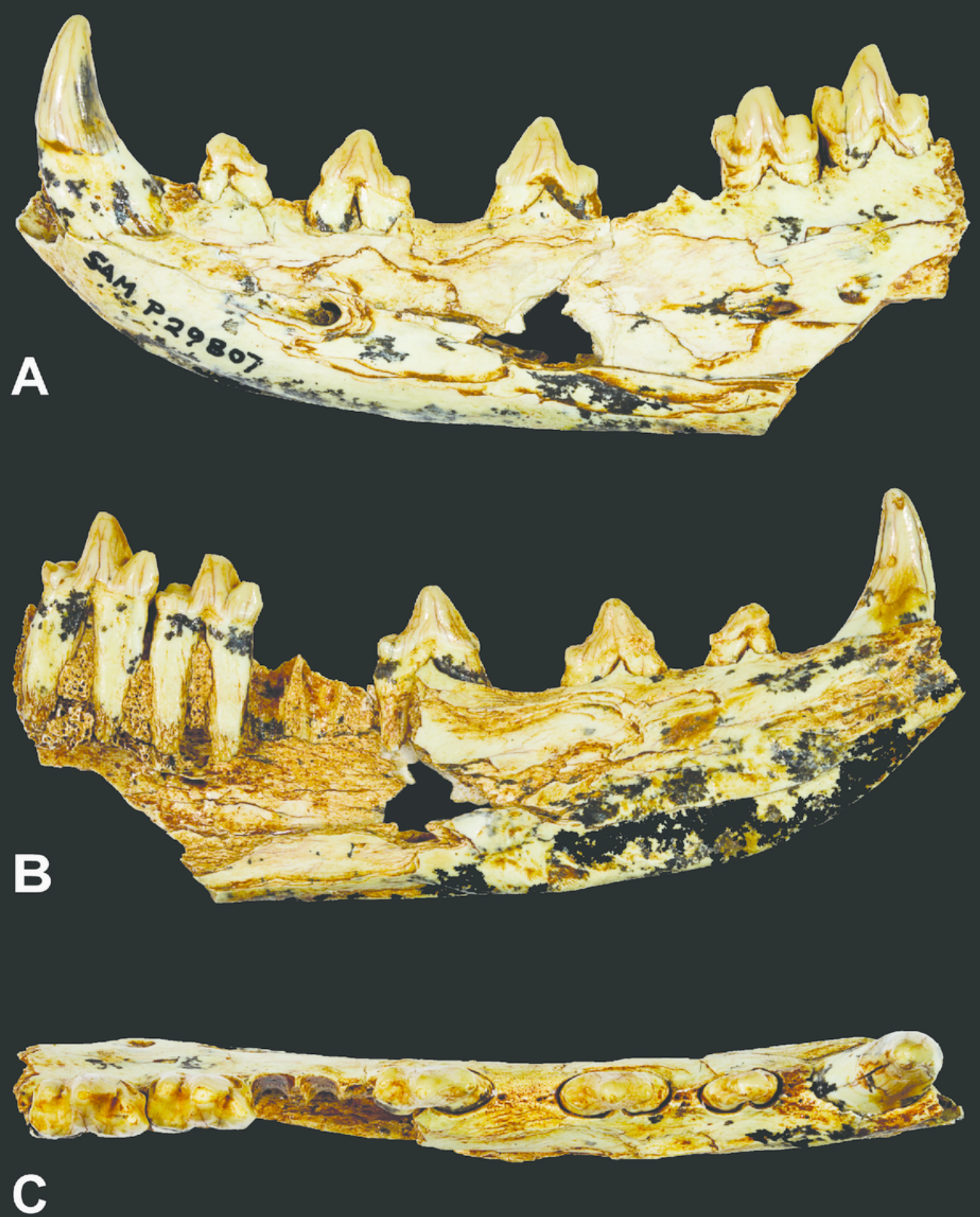
2

Thylacinus yorkellus holotype SAM P29807, incomplete left dentary.

Interpretive drawings of the specimen. (A) lateral view. (B) medial view. (C) dorsal view. Abbreviations: adl, anterior cuspidule; abdl, anterobuccal cuspidule; amf, anterior mental foramen; c, canine; cn, carnassial notch; end, entoconid; hld, hypoconulid; hyd, hypoconid; ia, incisor alveoli; m1-3, molars 1-3; p1-3, premolars 1-3; pad, paraconid; pcd, precingulid; pmf, posterior mental foramen; prd, protoconid; sym, symphyseal surface. Hatched areas represent broken bone surfaces, grey areas represent wear facets on the teeth. Scale bar = $50 \mathrm{~mm}$. 


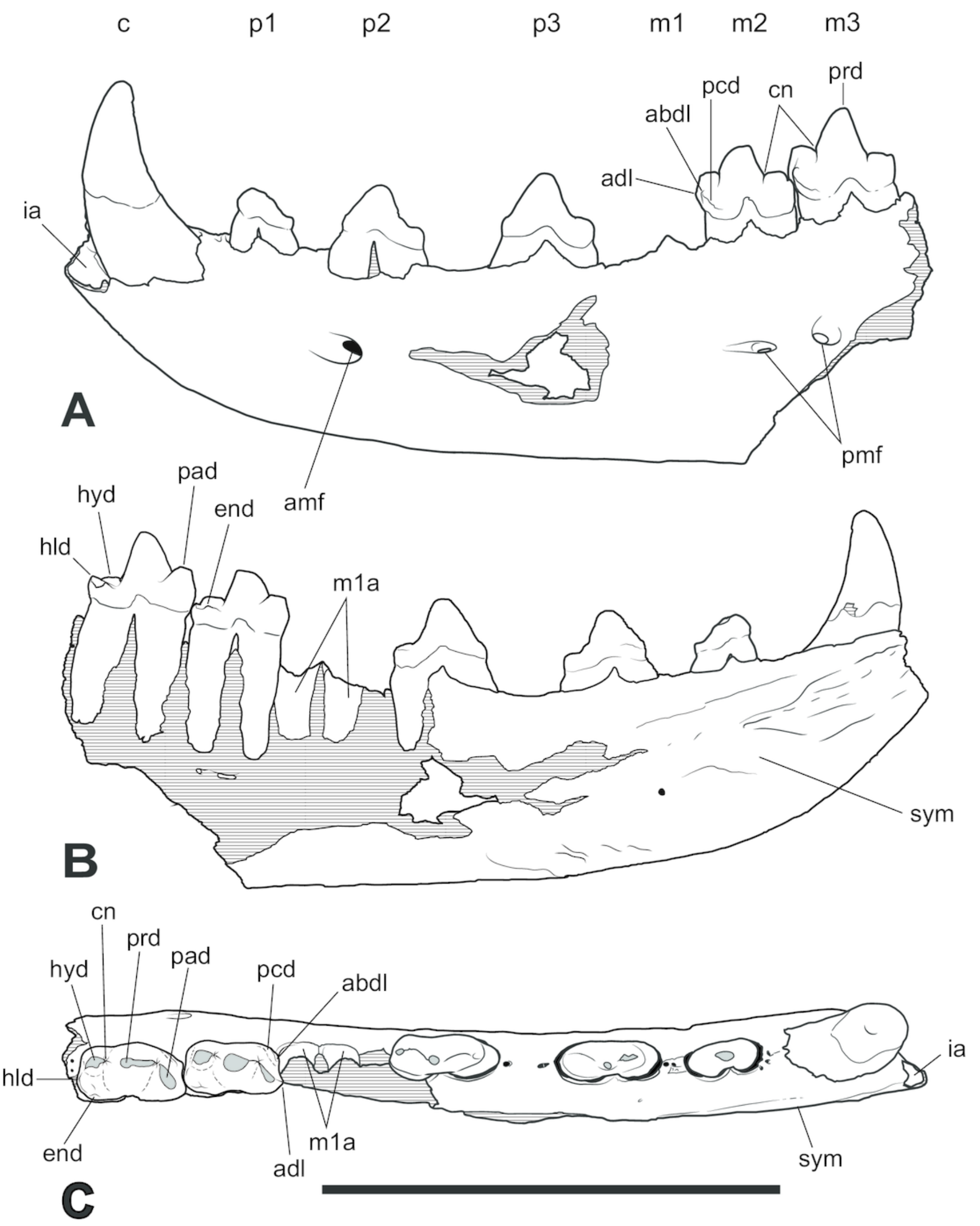


3

Thylacinus yorkellus, paratype SAM P38799, right $\mathrm{m}_{3 .}$

(A) photograph in buccal view. (B) photograph in lingual view. (C) interpretive drawing of $A$.

(D) interpretive drawing of B. Abbreviations: abdl, anterobuccal cuspidule; adl, anterior cuspidule; cn, carnassial notch; end, entoconid; hld, hypoconulid; hyd, hypoconid; pad, paraconid; pcd, precingulid; prd, protoconid. Scale bar $=10 \mathrm{~mm}$. Photographs by Steven Jackson. 


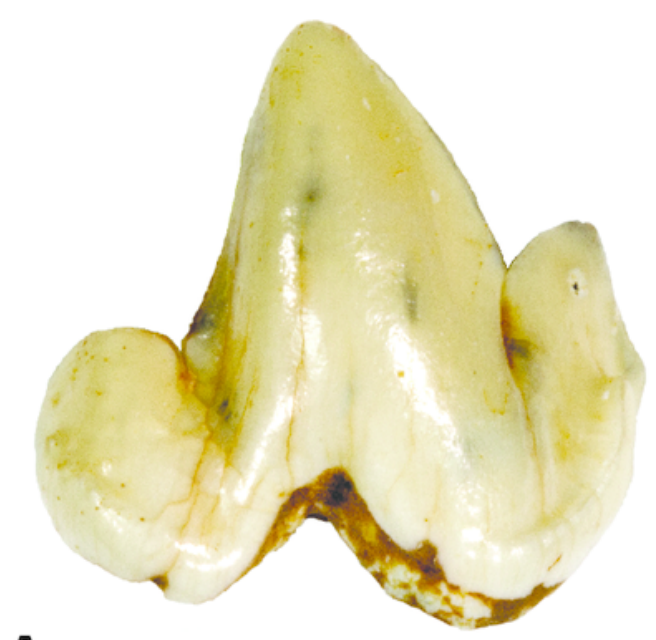

A

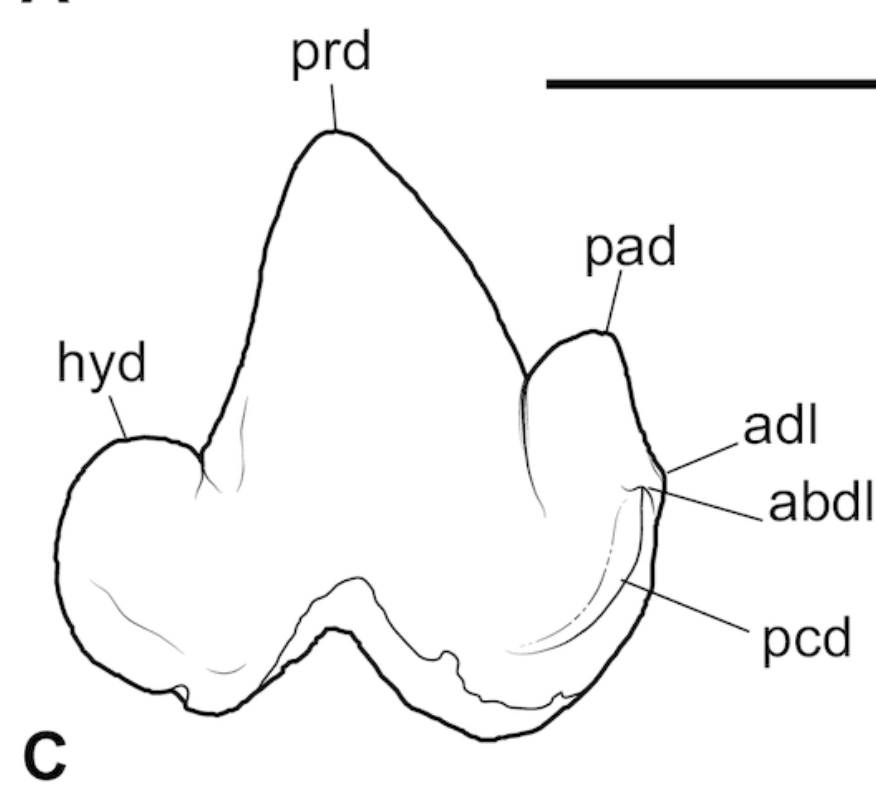

B

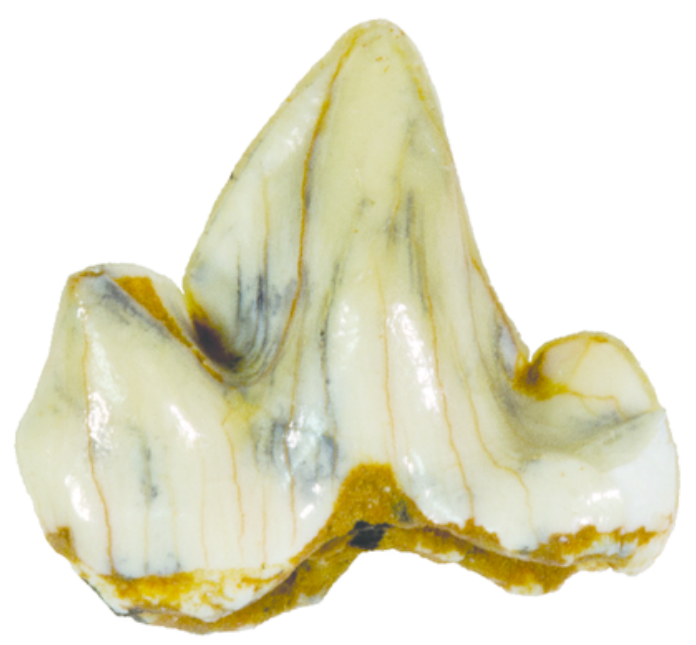

prd

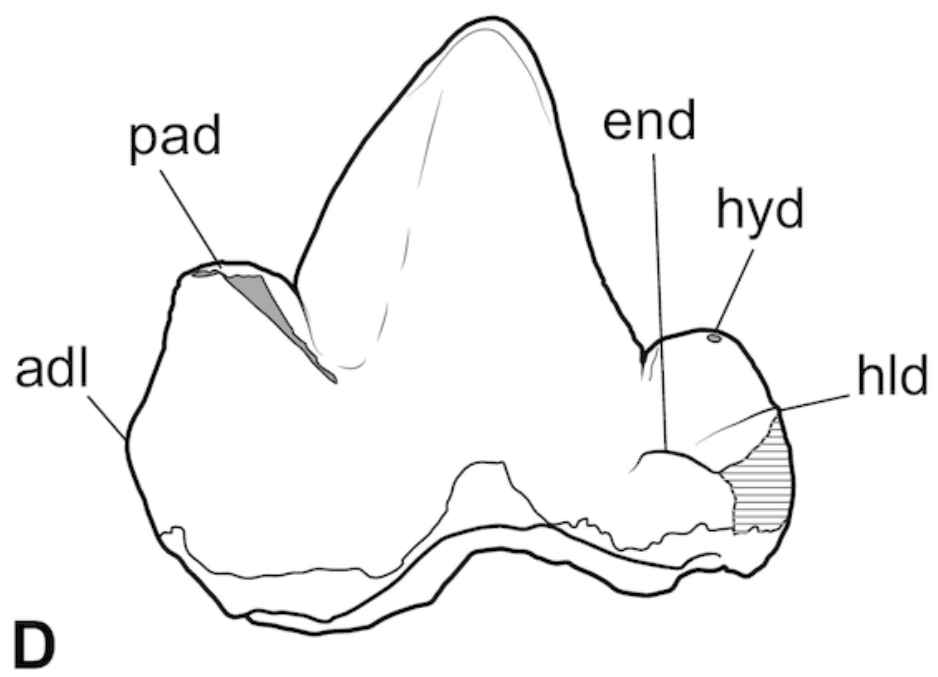


4

Thylacinus yorkellus, paratype SAM P38799, right $\mathrm{m}_{3}$

(A) photograph in anterior view. (B) photograph in posterior view. (C) photograph in occlusal view (D) Interpretive drawing of $A$. (E) Interpretive drawing of $B(F)$ Interpretive drawing of $C$. Abbreviations: abdl, anterobuccal cuspidule; adl, anterior cuspidule; cdo, cristid obliqua; cn, carnassial notch; end, entoconid; hld, hypoconulid; hyd, hypoconid; pacd, paracristid; pad, paraconid; pcd, precingulid; ppacd, preparacristid; pred, protocristid; prd, protoconid. Scale bar $=10 \mathrm{~mm}$. Photographs by Steven Jackson.

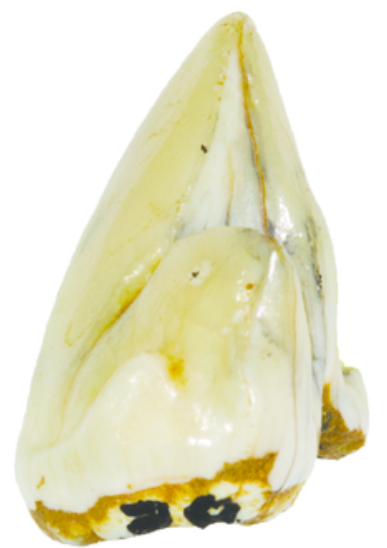

A

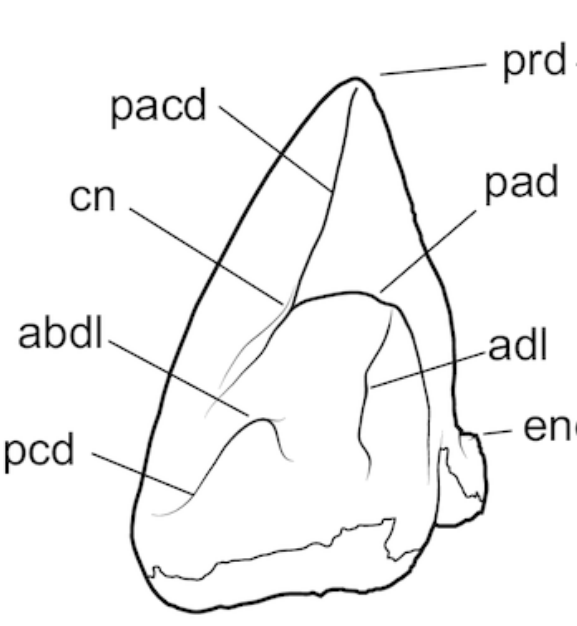

D

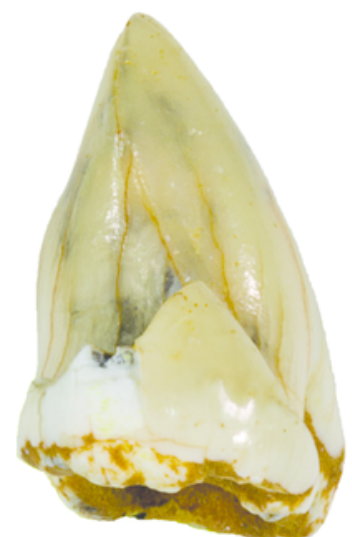

B

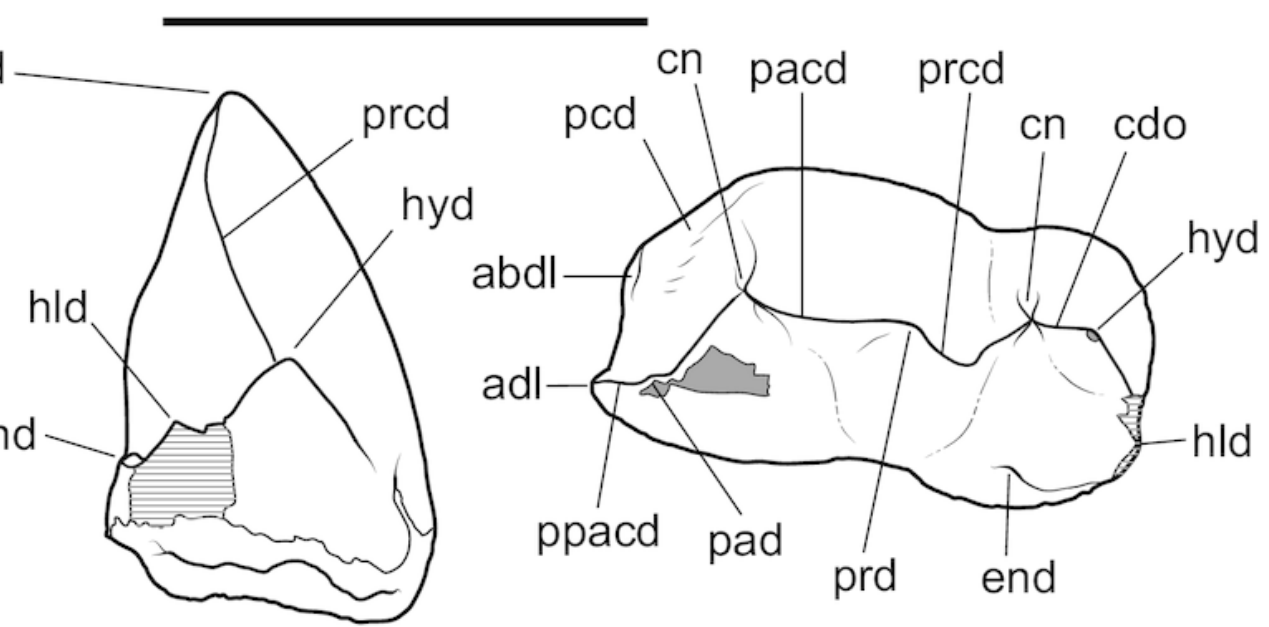

E

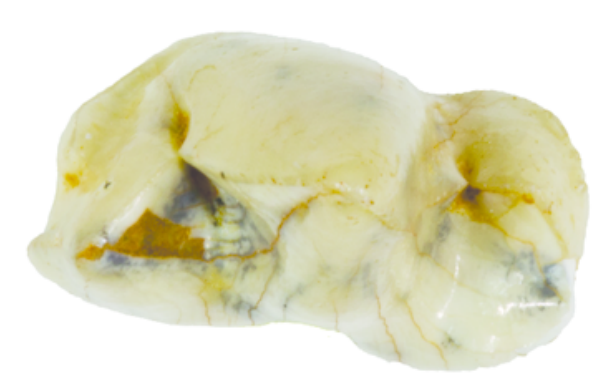

C

F 


\section{5}

Thylacinus megiriani, NTM P4376, fragmentary right dentary.

Monochrome photographs of the specimen after whitening with ammonium chloride. (A) lateral view. (B) medial view. (C) dorsal view. Scale bar $=50 \mathrm{~mm}$. Photographs by Steven Jackson. 


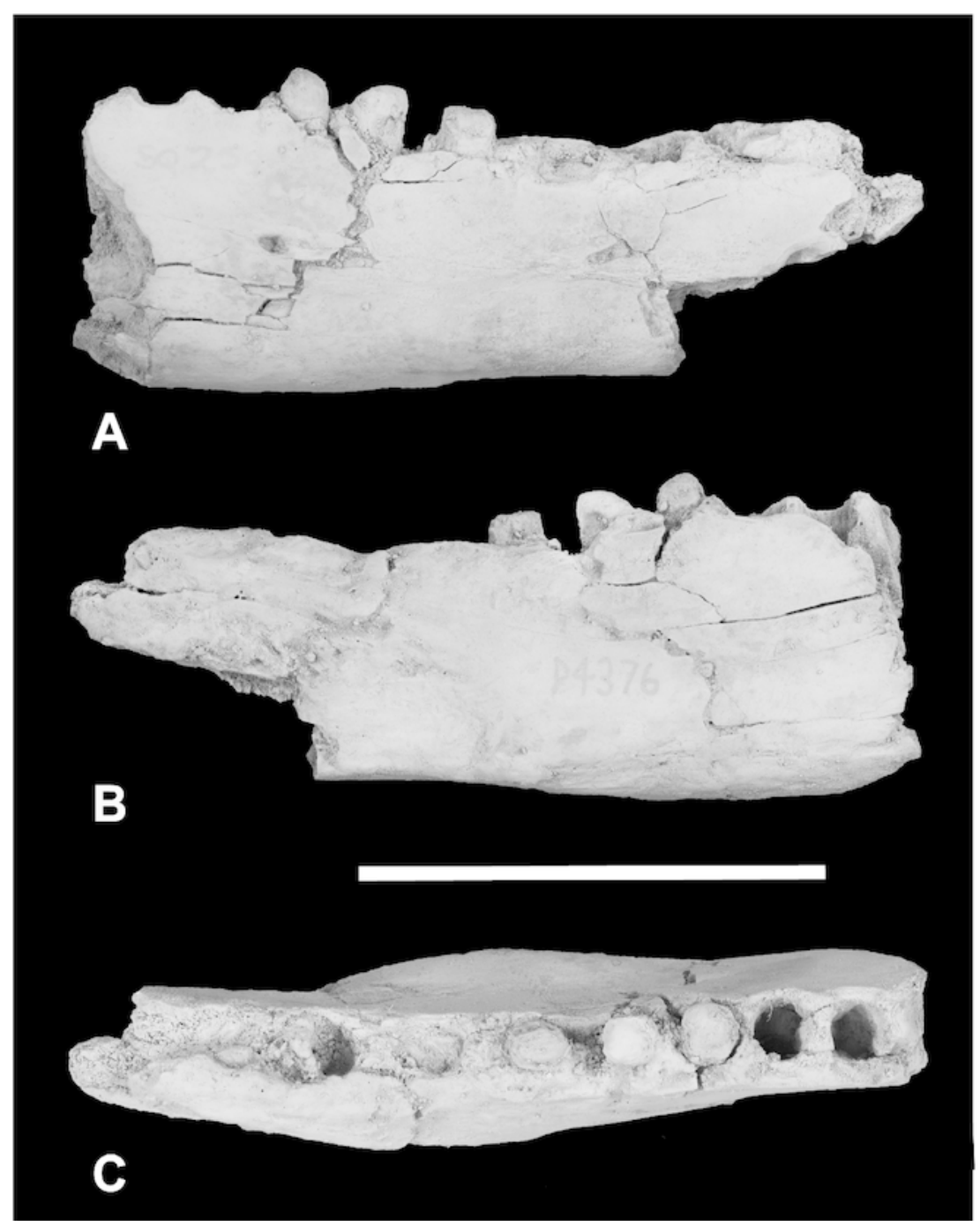


6

Thylacinus megiriani, NTM P4376, fragmentary right dentary.

Colour photographs of the specimen. (A) lateral view. (B) medial view. (C) dorsal view. Scale bar $=50 \mathrm{~mm}$. Photographs by Steven Jackson. 

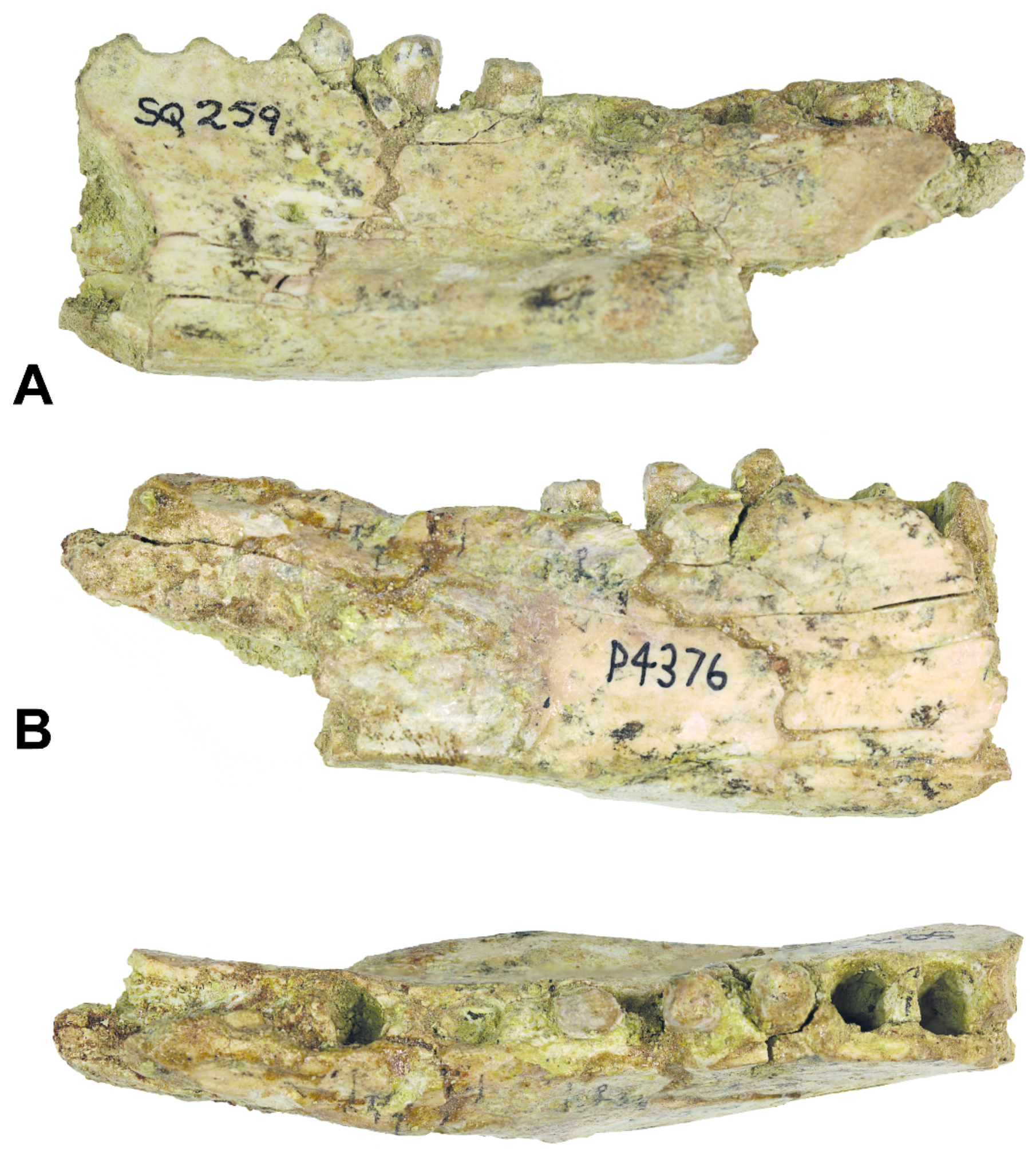

C 


\section{7}

Thylacinus megiriani, NTM P4376, fragmentary right dentary.

Interpretive drawings of the specimen. (A) lateral view. (B) medial view. (C) dorsal view. Abbreviations: amf, anterior mental foramen; m1-2, molars 1-2; mf, mental foramen; p1-2, premolars 1-2; pmf, posterior mental foramen; sym, symphyseal surface; vt, ventral torus. Hatched areas represent broken bone surfaces, grey areas represent patches of matrix. Scale bar $=50 \mathrm{~mm}$. 

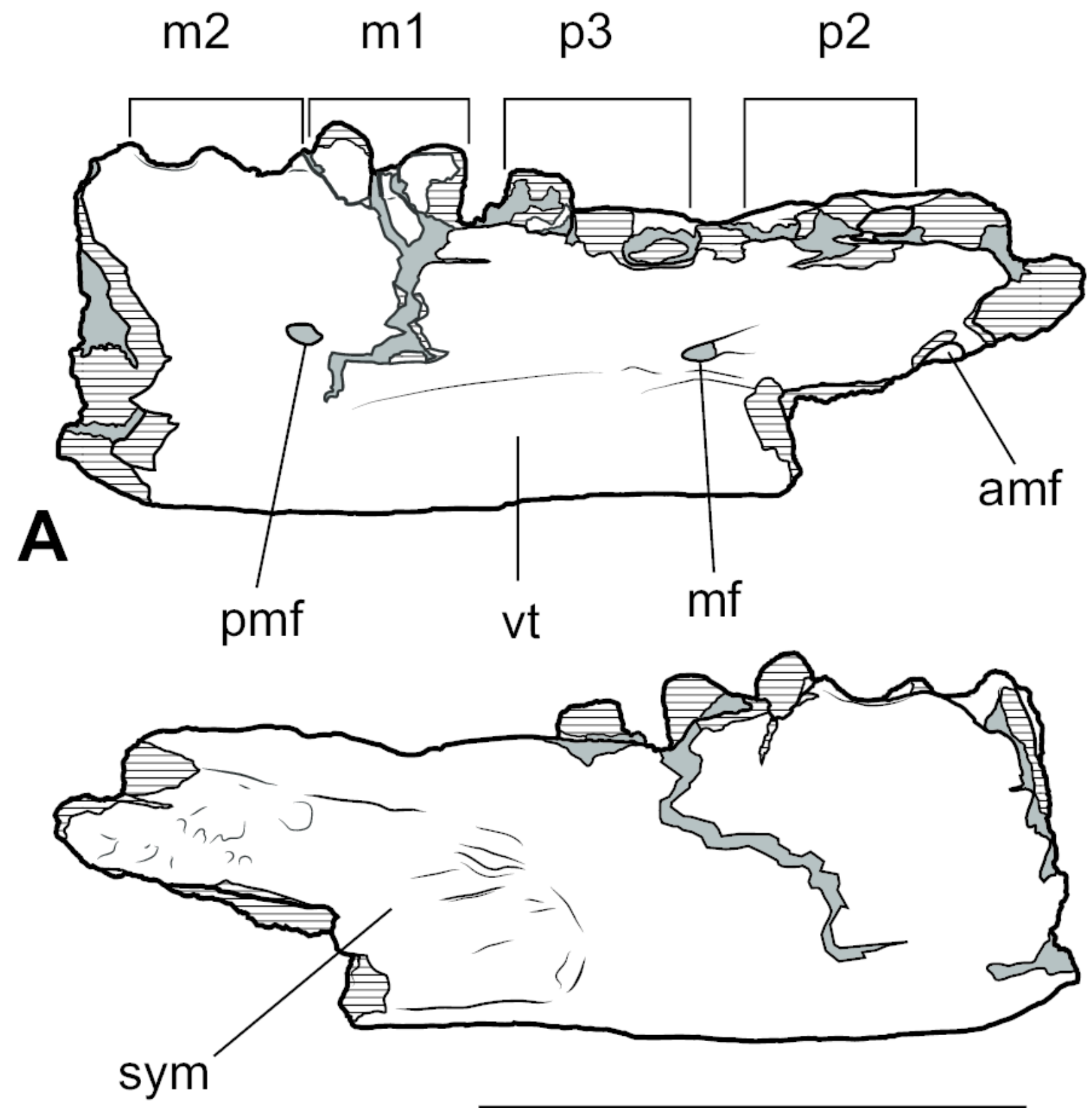

B

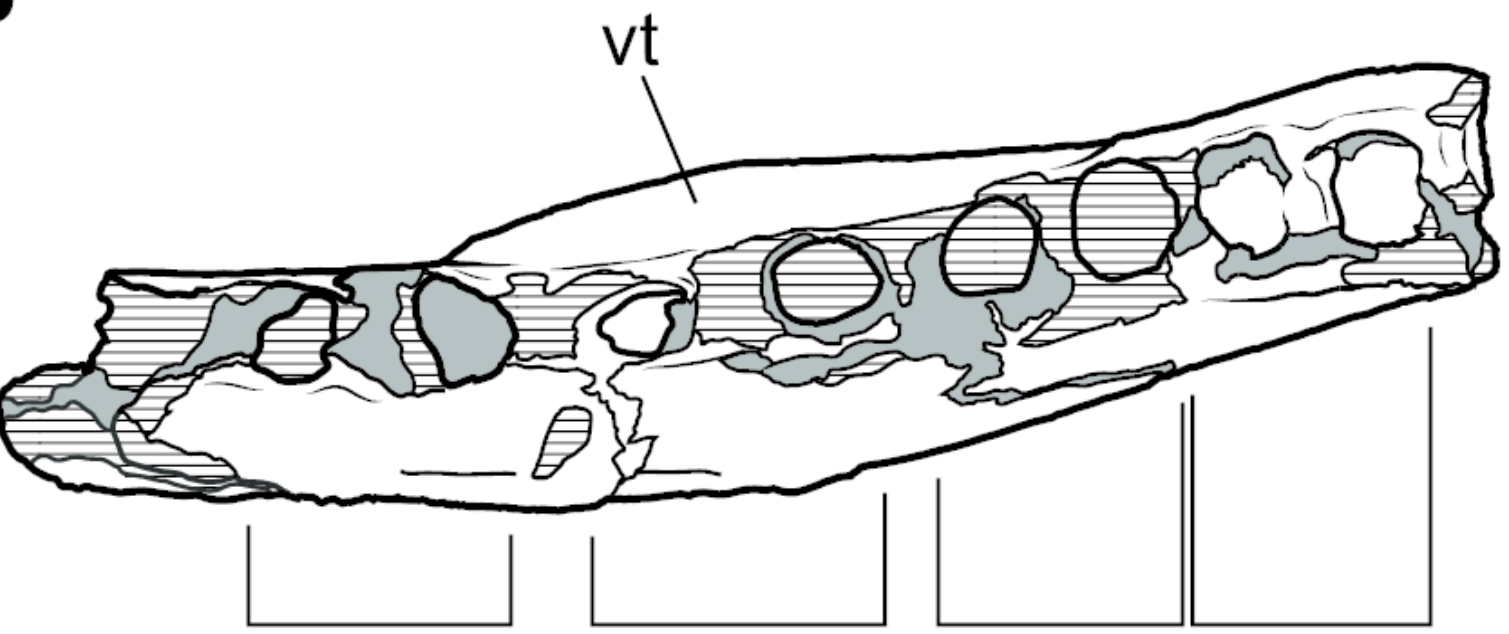

C

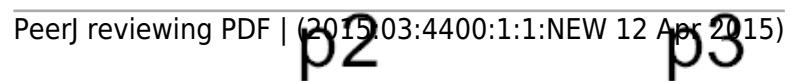

$\mathrm{m} 1$

$\mathrm{m} 2$ 
8

Thylacinus megiriani, NTMP4377, fragment of right dentary including partial right m4.

(A-C) monochrome photographs of the specimen after whitening with ammonium chloride.

(D-F) interpretive drawings of A-C. (A, D) lateral view. (B, E) medial view. (C, F) dorsal view.

Abbreviations: al, alveolus for anterior root of $\mathrm{m} 4$; cdo, cristid obliqua; $\mathrm{cn}$, carnassial notch;

$c p$, base of coronoid process; ed, entoconid; mcd, metacristid; md, metaconid; pcd, postcristid; prcd, protocristid; prd, protoconid. Grey areas represent patches of matrix, hatched areas represent broken bone or tooth surfaces. Scale bar $=30 \mathrm{~mm}$. Photographs by Steven Jackson. 


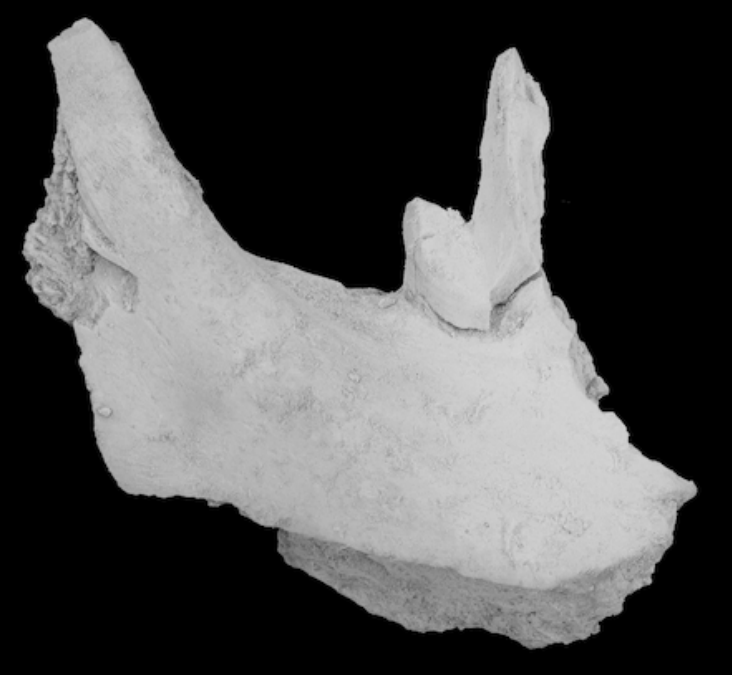

A

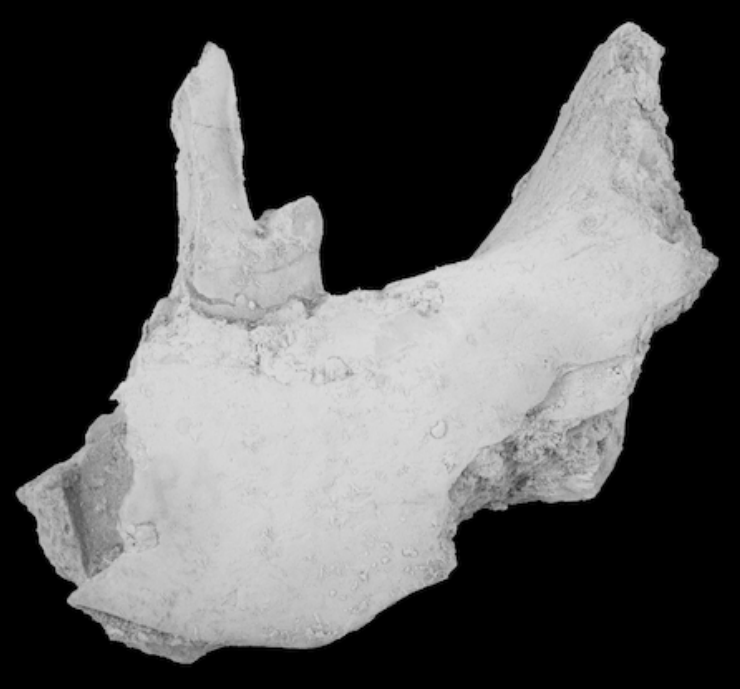

B

C
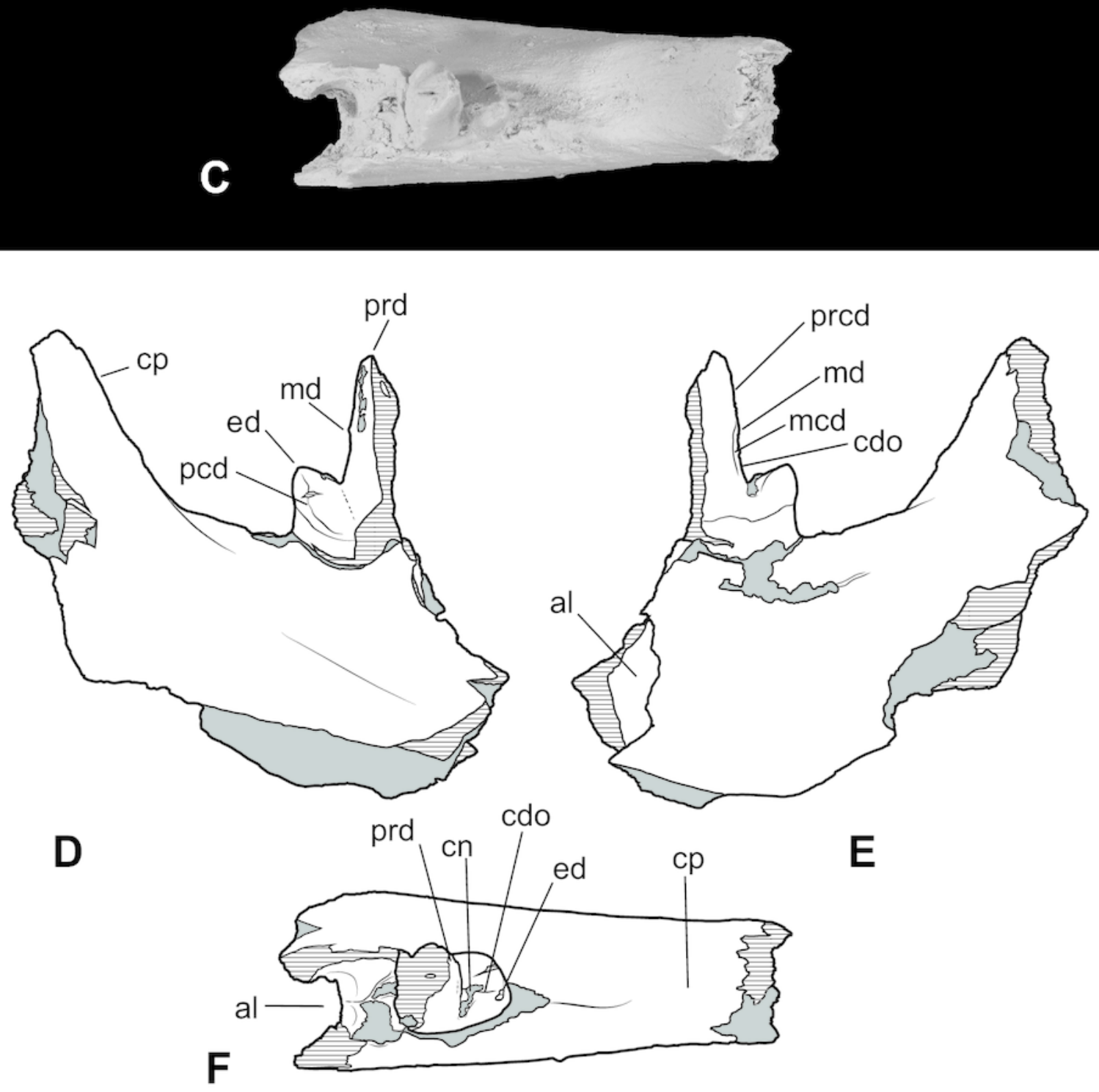
9

Thylacinus megiriani, NTMP4377, fragment of right dentary including partial right m4.

Colour photographs of the specimen. (A) lateral view. (B) medial view. Scale bar $=30 \mathrm{~mm}$.

Photographs by Steven Jackson.
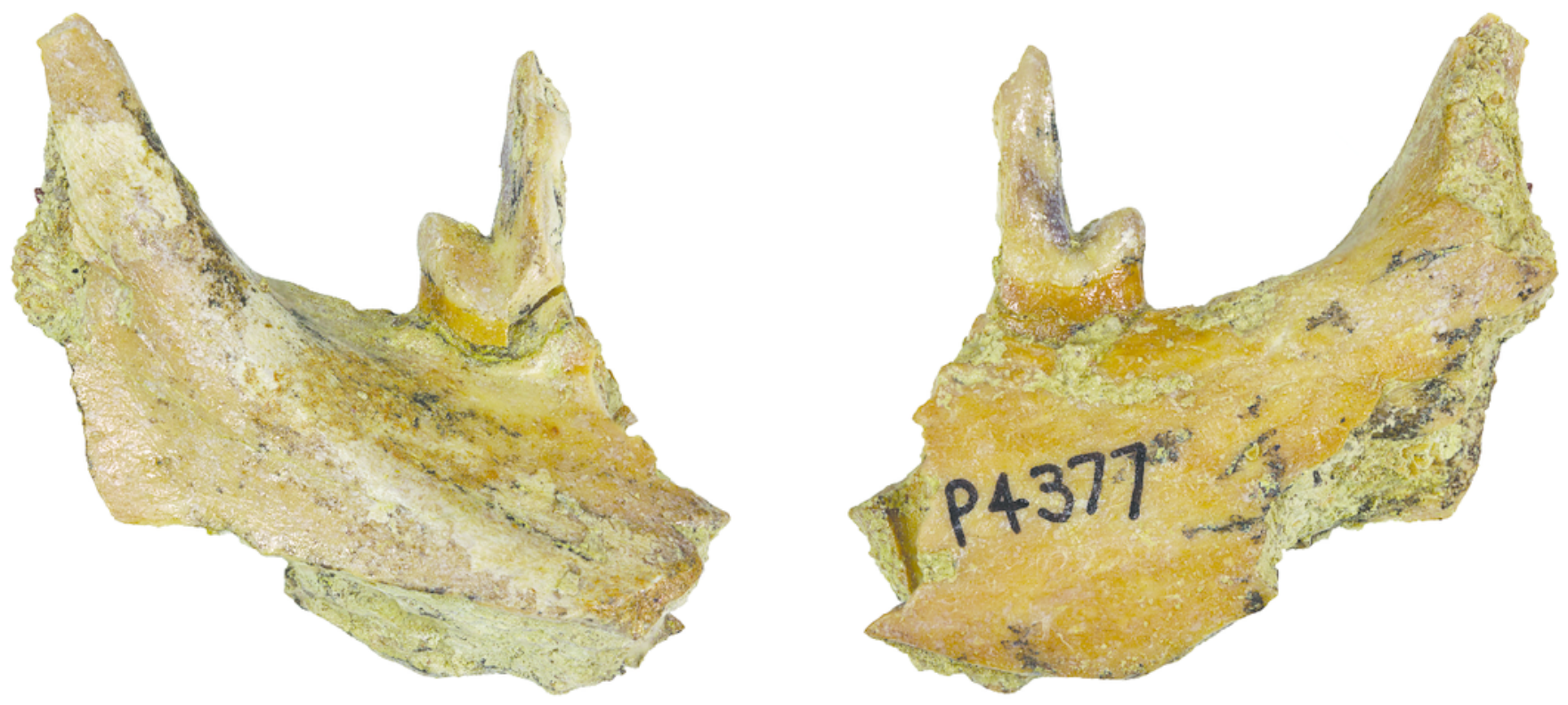

A

B 
10

Thylacinus megiriani, NTM P4377, right $\mathrm{m}_{4}$ in posterolingual view.

(A) photograph. (B) interpretive drawing. Abbreviations: cdo, cristid obliqua; hyd, hypoconid; mcd, metacristid; md, metaconid; prcd, protocristid; prd, protoconid. Grey areas represent patches of adherent matrix. Scale bar $=5 \mathrm{~mm}$. Photograph by the author.
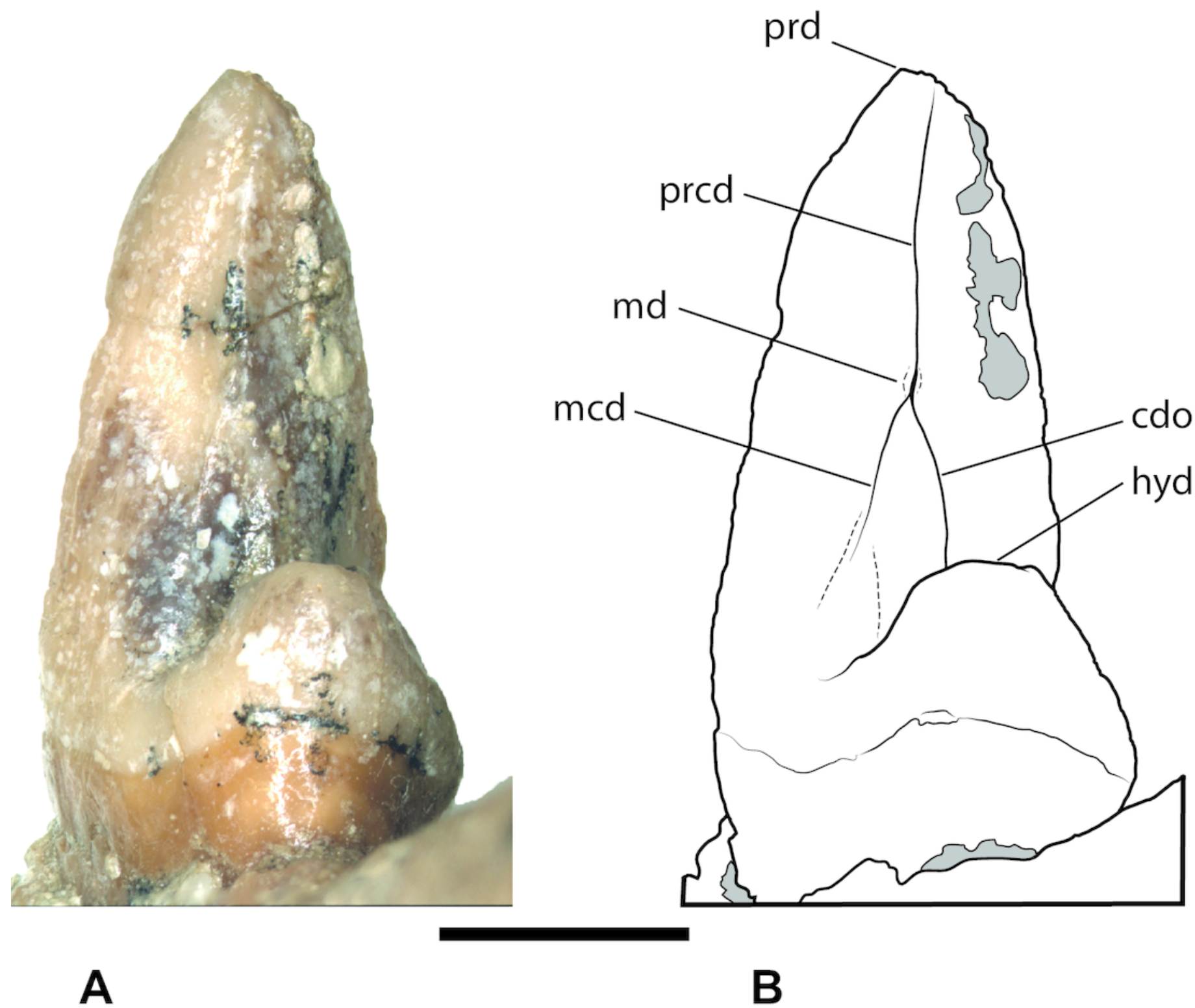
11

Results of the cladistic analysis of thylacinid interrelationships.

A) reduced cladistic consensus tree of two most parsimonious trees (tree length $=93$ steps) obtained after a posteriori pruning of Maximucinus muirheadae. (B) strict consensus with bootstrap support values for clades with values $>50 \%$. 


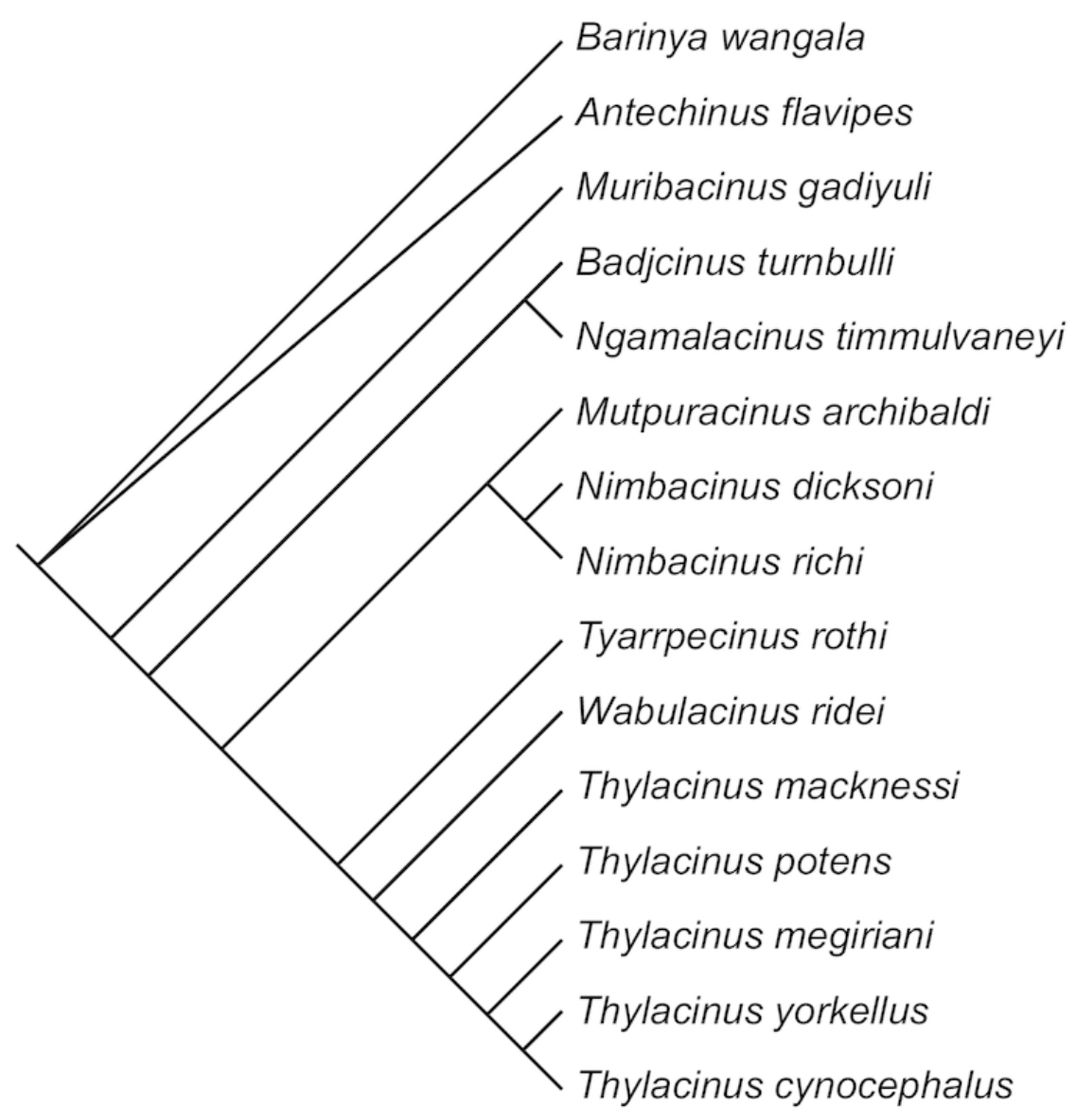

A

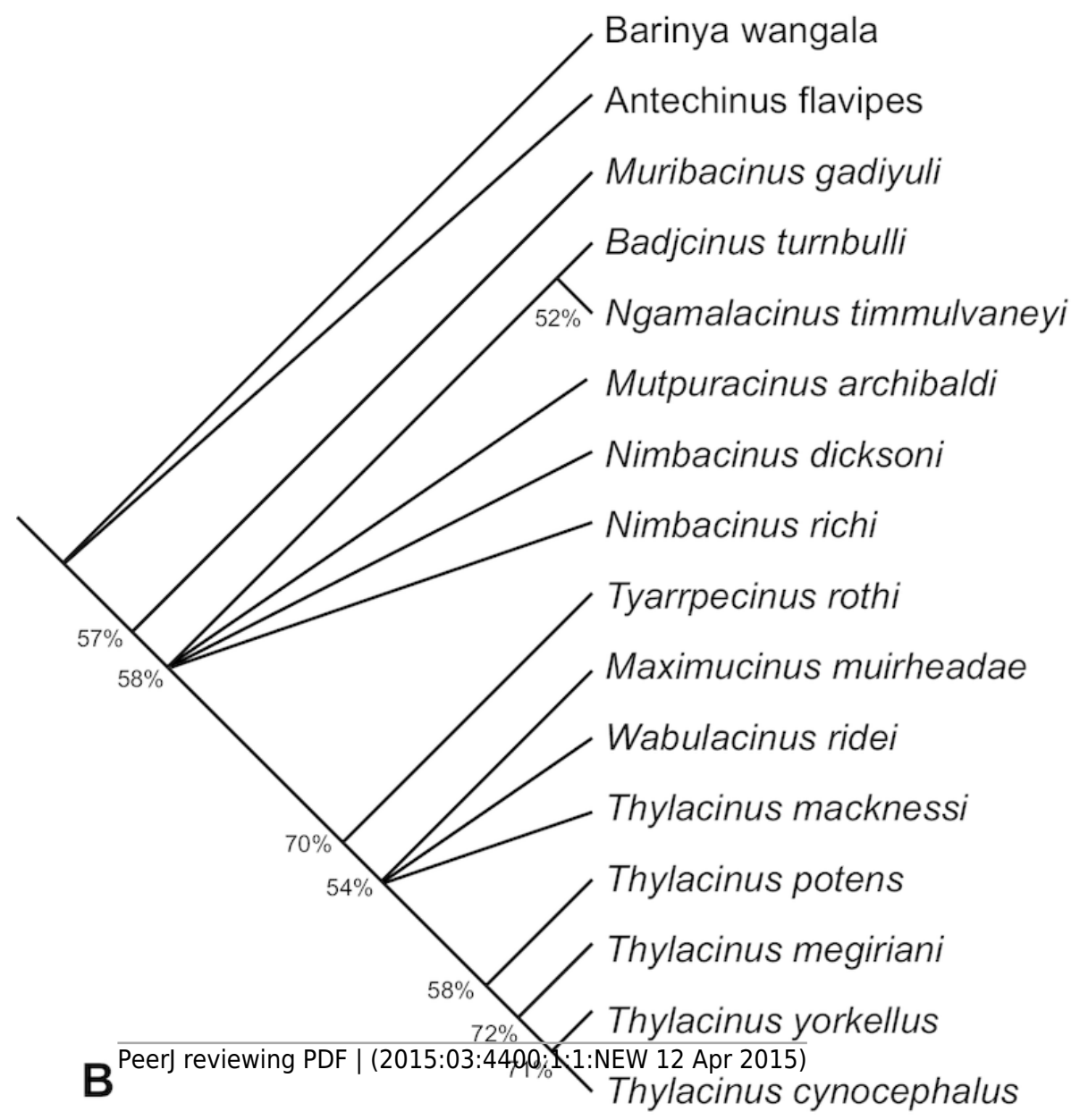


12

A phylogenetic tree of Thylacinus, calibrated to the geological timescale.

Note that the dates of Th. potens, Th. megiriani and Th. yorkellus are not tightly constrained and the ages given here are approximations with the grey bars indicating a range of plausible ages. Numbers represent ages in ma. Dates of boundaries taken from Cohen et al. (2013).

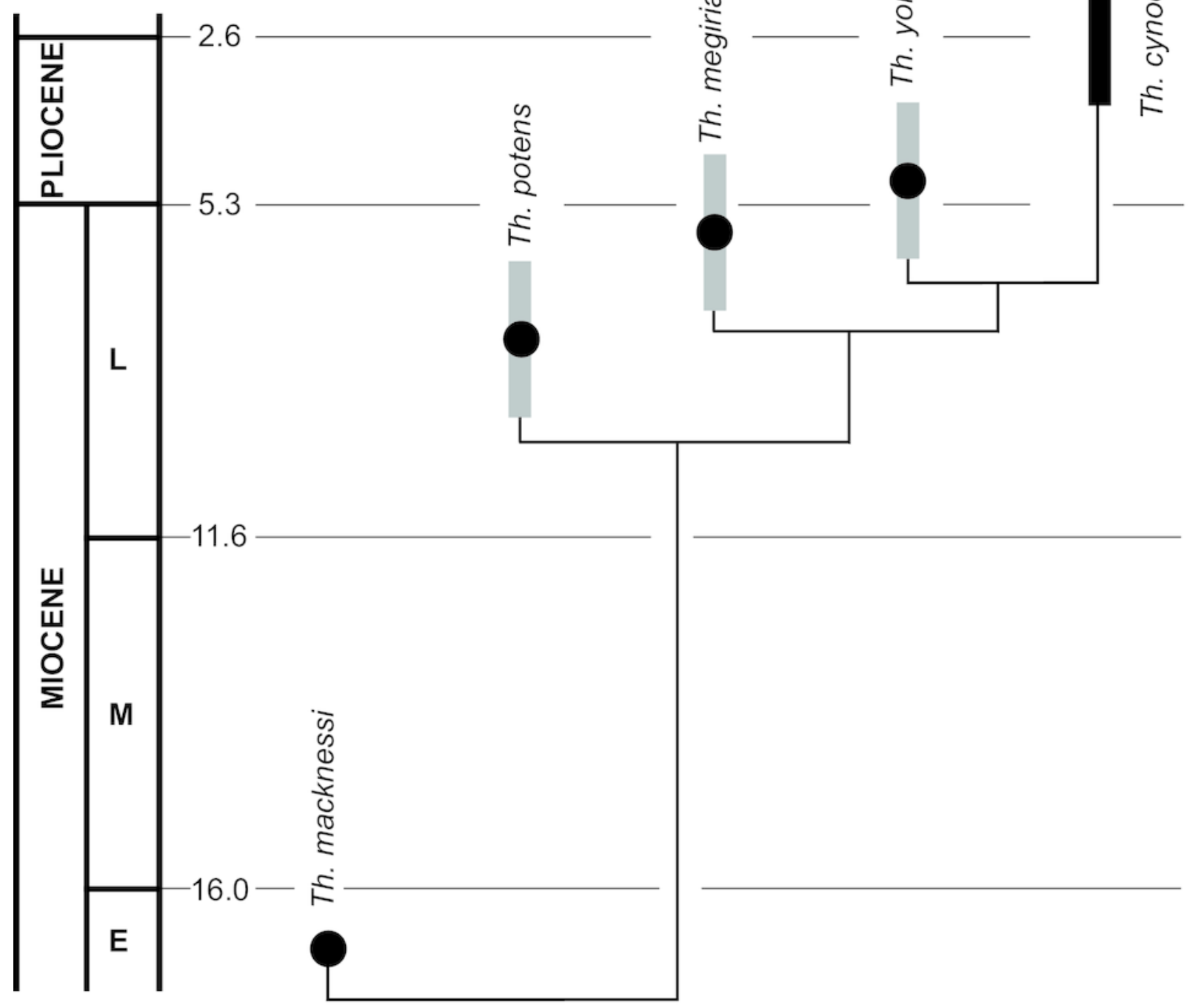




\section{Table $\mathbf{1}_{\text {(on next page) }}$}

Dental measurements of Thylacinus yorkellus.

Abbreviations: $H$, height of the crown, from crown-root junction to the apex; $L$, anteroposterior length of the crown (note that in the canine this measurement is taken at the base of the crown); $\mathrm{W}$, maximum buccolingual width of the crown; trigW, buccolingual width of the trigonid; talW, buccolingual width of the talonid. A ' $\sim$ ' symbol indicates that the measurement is approximate and is taken from the alveolus. 


\begin{tabular}{llllll}
\hline & $\mathbf{H}(\mathbf{m m})$ & $\mathbf{L}(\mathbf{m m})$ & $\mathbf{W}(\mathbf{m m})$ & trig W $(\mathbf{m m})$ & tal W $(\mathbf{m m})$ \\
\hline SAM P29807 & & & & & \\
$\mathrm{C}$ & 15.2 & 8.7 & 6.5 & - & - \\
$\mathrm{P}_{1}$ & - & 7.2 & 3.1 & - & - \\
$\mathrm{P}_{2}$ & - & 9.8 & 4.0 & - & - \\
$\mathrm{P}_{3}$ & - & 10.4 & 4.4 & - & - \\
$\mathrm{M}_{1}$ & - & $\sim 8.7$ & - & - & - \\
$\mathrm{M}_{2}$ & - & 11.0 & - & 5.5 & 12.0 \\
$\mathrm{M}_{3}$ & - & 12.0 & - & 6.5 & 5.7 \\
SAM P38799 & & & & & \\
$\mathrm{M}_{3}$ & - & 11.3 & - & 6.0 & 6.0 \\
\hline
\end{tabular}

3 


\section{Table 2 (on next page)}

Dental measurements of Thylacinus megiriani.

Abbreviations: $H$, height of crown, from crown-root junction to tip of protoconid; $L$, basal length; trigW, buccolingual width of trigonid; talW, buccolingual width of talonid. A ' ' symbol indicates that the measurement is approximate and is taken from the alveolus.

Measurements in brackets are taken as preserved and represent minimum values due to incompleteness of the specimen. 


\begin{tabular}{lllll}
\hline & $\mathbf{H}(\mathbf{m m})$ & $\mathbf{L}(\mathbf{m m})$ & $\operatorname{trigW}(\mathbf{m m})$ & talW $(\mathbf{m m})$ \\
\hline NTM P4376 & & & & \\
$\mathrm{P}_{2}$ & - & $\sim 15.6$ & - & - \\
$\mathrm{P}_{3}$ & - & $\sim 18.0$ & - & - \\
$\mathrm{M}_{1}$ & - & $\sim 14.3$ & - & - \\
$\mathrm{M}_{2}$ & - & $\sim 13.4$ & - & - \\
NTM P4377 & & & & \\
$\mathrm{M}_{4}$ & 16.9 & - & $(7.3)$ & 6.5 \\
\hline
\end{tabular}

3 